REGISTRO DE COMERCIO - COMPETENCIA

- Erercendo função meramente administrativa, falece ao Registro do Comércio competência para entrar no exame da validade dos contratos entre marido mulher, para o seu arquivamento.

\title{
MINISTÉRIO DO TRABALHO, INDÚSTRIA E COMERCIO
}

PROCESSO N. ${ }^{\circ} 116.039-43$

Murray, Simonsen \& Comp. Ltda., solicitando o arquivamento da alteração de seu contrato social. - Aprovo. Transmita-se.

(O despacho determina seja transmitido ao interessado o parecer to assistente técnico do teor seguinte: "Murray Simonsen \& Comp. Limitada, desta praça, apresentam ao Registro do Comércio, para o devido arquivamento, a alteração de seu contrato social, pela qual se retira da sociedare o sócio Roberto Simonsen, transferindo as suas cotas a Chares Roberto Murray e Wallace Simonsen, sócios, remanescentes, e à Sra. Maria Emília Simonsen, - espôsa dêste último pelo regime da comunhão de bens - que passa a fazer parte da sociedade. Opóe dúvida o Departamento Nacional da Indústria e Comércio sôbre a validade do contrato mercantil entre cônjuges. E, referin. do-se às opinióes controvertidas de Carvalho de Mendonça, Valdemar Ferreira, Spencer Vampré e Carvalho Mourão, de um lado e Alfredo Bernardes, Astolfo de Resende e Magarinos Tôrres de outro, junta um parecer do Dr. Anítal Freire, então Consultor Geral da República, opinando pelo arquivamento do contrato de James Magnus \& Comp. Limitada, em que figuravam camo sócios marido e mulher casados pelo regime de separação de bens, associados a terceiros. Diante de tais controvérsias e para obter a orientação sôbre a matéria é o seguinte o assunto submetido à elevada consideração de Vossa Excelência. Ouvido o senhor Consultor Jurídico, observa S.S. que a orientação aconselhada no mesmo parecer é a da permissão da sociedade no caso de cônjuges casados pelo regime da separação de bens, conclusão essa que deve prevalecer, pôsto que nenhuma lei sobreveio para determinar a sua modifica. ção. Na hipótese em aprêço, porém, a situaçãc é diversa - continua S. S.

Trata-se de uma sociedade por cota de responsabilidade limitada - de natureza mista - que é, ao mesmo tempo, uma sociedade de pessoas e sociedades bens. Neste caso, e considerando que - como observam os interessaclon - o capital já se acha integralizado, o fato de pertencerem as cotas a marida e mulher, casados pelo regime da comunhāo, não teré influência visto que há outro cotista e, porisso, não importa a quanłog pertençam as demais cotas. Assim, não influi na constituição da sociedade nem impede o seu funcionamento o fato de se integrarem as outras cotas num sá patrimônio conjugal. Entretanto, apreciando a questão da firma social que é atualmente Murray, Simonsen \& Comp. Ltda, observa o Sx. Consultor Jurídico que esta räo deverá prevalecer, pois que as cotas dos sócios casados pelo regime da contunhão de bens se integram num só patrimônio conjugal. Não há, pois, no qua concerne à sociedade, dois sócios, mas apenas um, representado pelo maxiclo. 
Assion, a seu ver, deve er exigida prèviamente a alteração da firma para Murray \& Simonsen Ltda., salvo se para a sociedado entrar outro cotista que justifique a conservação do aditivo "\& Comp.".

Preliminarmente, senhor ministro, parece-nos oportuna uma argüição de grande monta. Deve o Registro do Comércio entrar no exame da validade dos contratos entre marido e mulher, para o seu arquivamento? Parece-nos que não. Exercendo função meramente administrativa, êsse exame ultrapassa os limites de sua competência, não the cabendo, pois, ir além da verificação do cumprimento das formalidades enumeradas pelas leis vigentes. Esta asserçäo encontra apoio no Regulamento aprovado pelo Decreto n.o 93, de 20 de março de 1935, que dispōe : "Art. 24. No arquivamento dos contratos das sociedades comerciais nacionais, cumpre ao Departamento examinar so foram obedecidas as formalidades extrínsecas enumeradas no art. 302, ns. 1 , 2, 3, 4 e 6 do Código Comercial ou constantes, expressamente, de outros dispositivos legais, bem como verificar se figuram cláusulas contrárias à ordem pública e aos bons costumes, sem entrar na apreciação do modo por que são regulados os interêsses dos sócios".

Nāo cabe, assim, ao Registro do Comércio entrar na indagação de direito sôbre a natureza das cláusulas, mormente em questão como a presente que envolve matéria contenciosa cuja solução é da competência do poder judiciário. Não obstante, a questão tem sido vivamente debatida em várias repartiçōes de Registro do Comércio, cujas decisōes, pela diversidade de critérios, têm sido proferidas em sentidos os mais variados. Quanto ao mérito da consulta é de se observar que a legislaçāo brasileira é omissa no tocante à validade dos contratos mercantis entre cônjuges, ficando assim, como observa Aníbal Freire no seu parecer, campo aberto à interpretação por analogia e à aplicação dos princípios gerais de direito. Mas o princípio dominante no Brasil e com o qual está de acôrdo o Sr. Consultor Jurídico, parece que é o de admitir-se sociedade entre marido e mulher desde que, associados e terceiro, as suas cotas se integrem num só patrimônio. Dessa forma, como parece ao Consultor Jurídico, não deve sofrer impugnação, quanto so fato de figurarem, como sócios, marido e mulher, a alteração de contrato de Murray, Simonsen \& Comp. Ltda. Entretanto, data venia, discordamos do Sr. Consultor Jurídico quanto à exigência de ser modificada a razäo social para Murray a Simonsen Ltda. Não resta dúvida que, quanto aos bens dos sócios casados, há unidade de patrimônio, mas é também inegável que há dualidade de sócios. A sócia, uma vez admitida como tal, deve poder exercer as funçōes inerentes a essa sua qualidade e que the sejam atribuídas. Seria criar uma restrição de direito se fôsse ela impedida de agir ou de figurar na firma. As cotas dos sócios casados, embora representando um só patrimônio, säo distintas e êstes entram para a sociedade em igualdade de condições.

Não deve, pois, a constituição do capital ter influência na composição da firma. Se a mulher casada pode, em determinadas circunstâncias, ser sócia do marido e como tal figura no contrato, tem, como os demais sócios, os direitos e obrigações que lhe sejam atribuídos. O que não nos parece é que deva ela, como sócia, que é, ter negada a sua existência na organização porque - marido a representa. Neste caso, seria de completa inutilidade o seu ingresso na cociedade. Ademais, modificada que fôsse a firma para Murray \& Simonsen Ltda., não seria essa razēo social conforme à verdade. Carvalho de Mendonça, referindo-se aos sistemas que, sôbre firmas comerciais, oferece o 
direito comparado, diz que o terceiro sistema estabelece como princípios que a firma seja sincera, verdadeira (Tratado vol. II, n.o 181), Logo a seguir. afirmando que a lei brasileira adotou êsse terceiro sistema, observa qua firma deve ser a tiel expressão da verdade. Cita, ainda, o insigne mestre -... Direito Comercial, pág. 370 - a circular do Conselho Federal Sứço, de 20 de maio de 1883 e De Salis, "Le droit Federal Strisse", segunda edição, volume 4..$^{\circ}$ n. 1.643: "As razões comerciais devem ser conformes à realidade; o interêsse públìco o exige". Navarrine - Comp. ao Código Comercial, edição Vallardi, volume 2. ${ }^{\circ}$, pág. 245, in Antão de Morais, Parecer, Relatórł̧o da Junta Comercial de São Paulo de 1928, pág. 42 - também observa que "La ragione sociale deve reppresentare una formazione sociale, que non sia contrario al vera". Este princípio, adotado, como se vê, também por consagrados autores estrangeiros, aplicado ao caso que se discute, demonstra fàcilmente a impossibilidade da sdoção da firma Murray \& Simonsen Ltda., para distinguir uma sociedade composta de três sócios. Tal firma dá a idéia de que são dois os seus sócios componentes, quando, na verdade, são três, se betn que representado dois patrimônios. Fugiria ela à sua função precípua, que é exatamente a de informar a terceiros e não iludi-lo. Não vemos, pois, razões que justifiquem a mudança da firma atual de Murray, Simonsen \& Comf : Limitada, para Murray \& Simonsen Ltda. O que nos parece indispensával é que a sócia D. Maria Emília Simonsen apresente ao registro do Comércio a escritura de autorização para comerciar, como expressamente o exige o art. $1 .^{\circ}$, n. $^{\circ} \mathrm{A}$, do Cádigo Comercial. O nosso direito nåo admite a autorizaf̧ão tática. Deve ser expressa e por escritura pública. Éste é o nosso parecer que submetemos à elevada consideração de vossa excelência).

PROCESSO N. ${ }^{\circ} 143.078$

Junta Comercial do Estado de São Paulo, consultando sôbre a verdadeira interpretação dos despachos ministeriais relativos à composição das firmas Murray, Simonsen \& Comp. Ltda., e Valter Limitada. -- Aprovo. 'Transmitase e arquive-se. - ( $O$ despacho supra aprova o parecer do $\mathrm{Sr}$. Assistente Técnico do teor seguinte : "O que se decidiu, no primeiro caso, é que, sendo a fïrma composta de três sócios, não poderia ela adotar a razão Murray \& Simonsen Ltda., pôsto que o sistema adotado pela lei brasileira, sôbre firmas comerciais, estabelece como princípio que as razōes sociais devem ser confcrmes à realidade. 'Tal firma daria a idéia de que são dois os seus sócios coraponentes, quando na verdade são três. Fugiria ela, assim, à sua função precípua, que é exatamente a de informar a terceiros e não iludi-los. Quanto à composição da firma Valter Ltđa., decidiu êste Ministério que o Decreto n. ${ }^{\circ}$ 3.708, de 1919, que criou as sociedades por cotas de responsabilidacle limitada, não seguiu a regra do Decreto n. ${ }^{\circ}$ 916, de 1890. Disciplínou de modo diverso a instituição das fîrmas ou denominaçóes, permitindo a individualização de apenas um sócio desde que o nome seja seguido da palavra limitada, designativa da existência de sociedade. Foi omitida a exigência do acréscimo da alocução - \& Companhia. Na hipótese vertente o sistema do De. creto n. ${ }^{\circ} 3.708$ foi obedecido. Está individualizado o sócio Valter com o acréscimo da expressão limitada que por si só revela a existência de ưn ou mais sócios. Este é o nosso parecer que submetemos à alta apreciação de Vosa Excelência") (A.M.F.). 